\title{
Pleomorphic Adenoma of Nasal Cavity
}

\author{
Atul Kansara, Hon. Asst. Prof. of E.N.T. at L.G. General Hospital and N.H.L. Municipal \\ Medical College and K.M. School of Postgraduate Studies, Ahmedabad \\ H.L. Ravi, Resident Medical Officer, \\ L.G. General Hospital, Ahmedabad, India.
}

Minor salivary glands tumours are very rare in nose, paranasal sinuses and in nasopharynx. Pleomorphic Adenoma of minor salivary glands may occur some times in that area which is usually of benign variety.

Here we report a case of a male, aged 44 years, presented with a mass in his rt. nostril which turned out to be Pleomorphic Adenoma of minor salivary gland. A brief review of the literature and management of the case is discussed herewith.

\section{INTRODUCTION}

Pleomorphic Adenoma have long been known to arise in the mucosal glands and are common in palate than to parotid gland. It is very rare to occur in nose and paranasal sinuses.

Pleomorphic Adenomas are also called a Mixed Tumours because histologically they are solid, tubulo-glandular structures alternate with myxoid and choronoid zones.

Incidence of Pleomorphic Adenoma in nose and paranasal sinuses has been reported as $7 \%$ by McDoland and Havens and $3 \%$ only by Spiro et al (1973).

\section{CASE REPORT}

A 44 years old male patient presented to us with complain of gradually increasing nasal blocked on right side since 3 months. There was no complain of common cold, sneezing and epistaxis. There was also no complain pertaining to throat and ear.

Past history: We had performed Endoscopic nasal surgery for removal of mass from Left Nostril before 2 years and its histopathology report was Pleomorphic adenoma of salivary gland. At present there is no complain on left side.

On Local Examination : Externally nose appeared normal.

Anterior Rhinoscopic Examination : There was a smooth mass seen on Right side arising from middle meatus. On palpation with cotton probe it was firm in nature and did not bleed on touch. Left side of nostril was found to be clear and normal.

Throat and Ears were normal.

Investigation: (Fig.1) Routine Haemogram and Urine examination revealed no abnormality. CAT

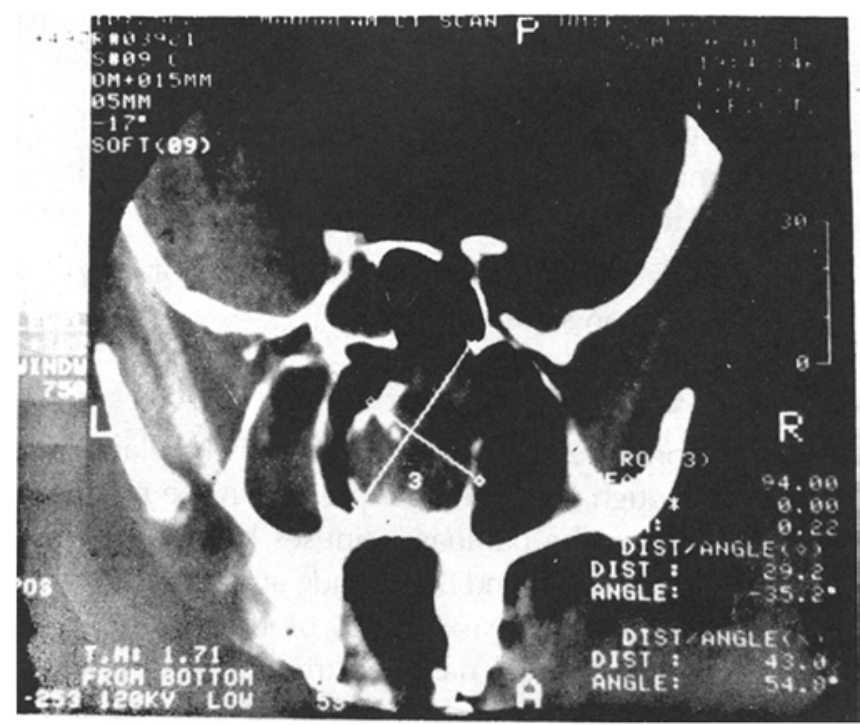

Fig-1

CT scan of Nose \& Paranasal air sinuses showing mass in it Nasal cavity. 
Scan of nose and paranasal sinuses confirmed the mass in Right Nostril more on the choanal side and not involving any other paranasal sinuses. Left side of the nostril no abnormality detected.

Operation : Considering mass to be of benign nature and past experience of removing similar

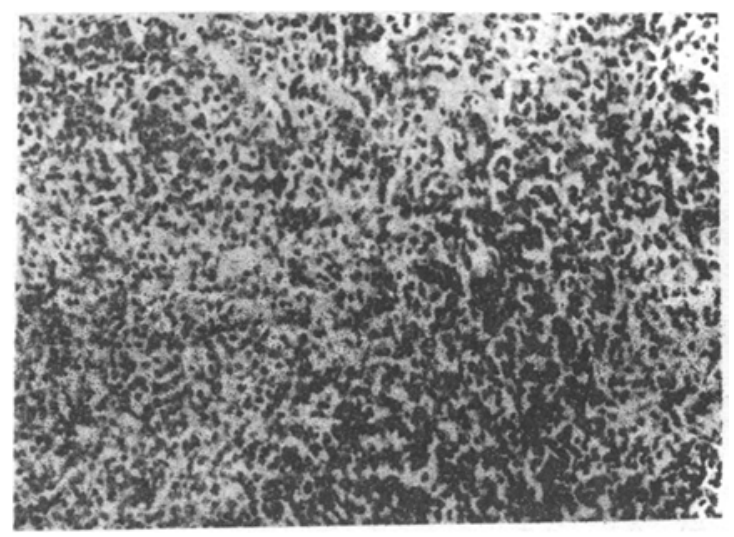

Fig-2

Photo micrograph of pleomorphic adenoma

type of mass from left nostril before two years, and without recurrence this time also mass was removed Endoscopically and in piecemeal. Histopathologically again it proved to be of Pleomorphic Adenoma of minor Salivary gland (Fig.2).

There is no sign of any recurrence or any complication so far.

\section{DISCUSSION}

Pleomorphic Adenoma of minor salivary gland, even though it is rare, can present in the nasal cavity or in the paranasal sinuses between the age group of 2 nd and 8 th decade and there is no predilection for sex. Most of the patients complains of local nasal obstruction and very epistaxis. In nose and paranasal sinuses, nasal cavity is the commonest site and than comes maxillary sinus. Grossly they appear asfirm, sessile, smooth or lobulated mass, sharply circumscribed. On cut section there is opaque white areas are seen with translucent zones indicating myxoid component.

Histopathology : The Pleomorphic Adenoma of minor salivary gland has the same histopathology features of that major salivary glands. The porportion of epithelial and stromal components bears no relationship to behaviour of the tumour. There may be some solid cellular tubuloglandular zones alternate with myxoid or chondroid zones. Squamous metaplasia may be seen sometimes on light microscopy. Tubules lined by cuboidal epithelium are diastase fast PAS positive. Peripheral palisading of tubular structures underlines the derivation of connective tissue component from the "myethelium". The myxochondroid areas are usually PAS negative. The stomal cells are usually diastase labile PAS positive. They some times give the impression of cribriform pattern and confusible with cribriform adenocarcinoma.

Aetiopathogenesis: The cause of the tumour is unknown, however they are basically accepted to be of ectodermal origin being drived from epithelial and myoepithelial cells. The later may become fibroblasts or chondroblasts.

Behaviour : Recurrence has not been reported in the majority of published cases. Miller (1964) reported recurrence of a nasal tumour but in that case diagnosis of malignancy having been made on the original biopsy. Primary malignant pleomorphic tumour is extremely rare. Eneroth (1964) estimated an incidence of malignant change in about $2 \%$ of major salivary gland pleomorphic tumours.

\section{CONCLUSION}

The diagnosis of Pleomorphic Adenoma is purely based on histopathology examination. Being benign variety, after complete removal, recurrence is very rare. Malignant changes may sometimes supervene over benign variety, so regular follow up of the patient is of utmost importance. 


\section{References}

1. Bergman F. (1969): Tumours of the minor salivary glands. Cancer $23: 538-543$.

2. Inrich Friedman. and Denis : Pathology of granulomas and paranasal sinuses : Chapter 14 : page 150-152

3. Martis, C.S., Karakasis D T (1971) : Pleomorphic Adenoma arising in the maxillary sinus. Plastic and Reconstructive Surgery $47: 290-292$.

4. Ronald H Spiro et al. (1973): Tumours of minor salivary glands Cancer $23: 117-129$.

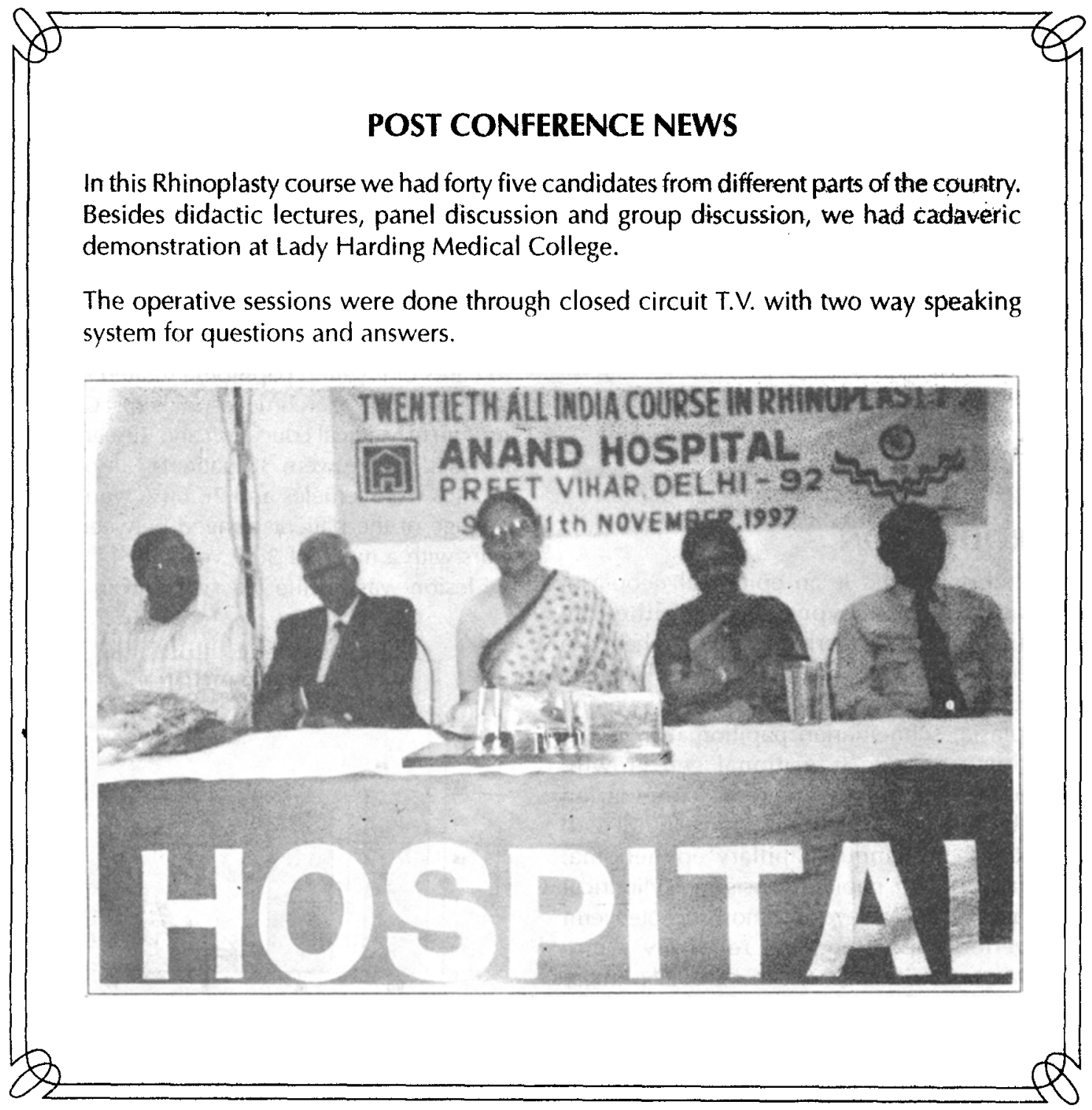

